\title{
ĐIỀU TRỊ PHẪU THUẬT LAO CộT SốNG CỔ ĐANG HOẠT ĐộNG
}

\section{TÓM TẮT}

Muc tiêu nghiên cứu: đánh giá kết quả điều trị phẫu thuật, tính an toàn và hiệu quả của lồng kéo giãn ADD khi lao cột sống cổ đảang hoạt động. Đối tượng và phương pháp nghiên cứu: 31 bệnh nhẫn lao cột sống cổ có biến chứng thần kinh được phẫu thuật lối cổ trước, thời gian từ 1/2015 đến 30/9/2017. Chia thành 2 nhóm: nhóm I chỉ ghép xương mào chạu tự thân $(n=15)$ và nhóm II phẩu thuật đặt lồng kéo giãn $A D D^{\text {plus }}$ (16 bệnh nhân). Theo dổi trước và sau điều trị bằng các thang điểm (VAS), JOA, NDI, góc gù, góc ưỡn cột sống cổ, và độ liền xương. Kết quá nghiên cứu: 31 bệnh nhân (24 nam và 7 nữ), tuổi TB $46,5 \pm 15,92$; cao nhất 78; thấp nhất 21 tuổi. Trước mổ: (VAS TB 5,39 $\pm 1,5$ điểm; ở lần khám cuối cùng VAS là $0,14 \pm 0,4$ điểm; JOA trước mổ $8,48 \pm 4,4$ so với sau mổ $16,78 \pm 0,65(p=.000)$; NDI trước mổ $42,9 \pm 4,0$ và sau mổ $10,16 \pm 5,9(p=0,001)$, góc gù vùng $18,9^{\circ} \pm 9,4^{0} ;$ góc $C L 3,03^{\circ} \pm 9,8^{\circ}(p=0,022)$ ơ lần khám cuối cùng góc gù vùng $-2,67^{\circ}$ và $\mathrm{CL}-9,4^{0}$; góc gù vùng ở lần khám cuối cùng so sánh giữa nhóm I $\left(4,14^{0} \pm 12,3^{0}\right)$ với nhóm II $\left(-7,0^{0} \pm 4,0^{0}\right)$ với $\mathrm{p}=0,015$; thời gian phẫu thuật nhóm I $(105,0 \pm 23,4)$ và nhóm $\operatorname{II}(138,1 \pm 40,6)$ phút với $p=0,01$. Không gặp các biến chứng lớn. Kết luận: điều trị phẫu thuật lao cột sống cổ có biến chứng thân kinh có ứng dụng ADD ${ }^{\text {plus }}$ bước đầu hiệu quả, không gặp biến chứng nào liên quan đến $A D D^{p l u s, ~ k h o ̂ n g ~ b i ̣ ~ đ a ̀ o ~ t h a ̉ i ~ d u ̣ n g ~ c u ̣, ~}$ xương ghép.

Tư khóa: lao cột sống cổ, phẫu thuật lao cột sống cổ, lồng kéo giãn trong lao cột sống cổ

\section{SUMMARY \\ APPLY ADD ${ }^{\text {plus }}$ OPERATED TREATMENT OF ANTERIOR CERVICAL TUBERCULOUS SURGERY WITH ACTIVE CERVICAL SPINE TUBERCULOSIS}

We prospectively studied 31 patients who cervical spine tuberculosis (CST) with complicated spinal cord in anterior operating. Time bound from January $1^{\text {st }}$ 2015 to September 30th 2017. Purpose: evaluated result treatment operating cervical spine tuberculosis. Result: total of 31 patients who diagnosed and operated, 24 men and 7 women, average age is 46,5 $\pm 15,92$; maximum 78 and minimum is 21 . Local kyphosis of cervical spine (LKC) average is $18,9^{0} \pm$ 15,92; and cervical lordosis $(C L) 3,03^{\circ} \pm 9,8^{\circ}$. At finally examination $C L$ is $-9,4^{0}(p=0,022)$. Group I loss of correction is $4,14^{0} \pm 12,3^{0}$ compared to Group II $7,0^{0} \pm 4,0^{\circ}$ with $\mathrm{p}=0,015$. JOA preoperated $8,48 \pm 4,4$

*Bệnh viện Phổi Trung ương

Chịu trách nhiệm chính: Nguyễn Xuân Diễn

Email: chirnguyenxuandien@gmail.com

Ngày nhận bài: 7.9.2021

Ngày phản biện khoa học: 27.10.2021

Ngày duyệt bài: 9.11.2021

\section{Nguyễn Xuân Diễn và cộng sự*}

compared to at final examination $16,78 \pm 0,65$ with $p=0,00$. NDI preoperated and postoperated 3 months $42,9 \pm 4$ and $10,16 \pm 5,9$ with $p=0,001$. No patient has complication related to $A D D^{\text {plus }}$ and autograft. Conclusion: Operate and apply ADD plus in active CST effectively and safely and uneliminatedly.

\section{I. ĐẶT VẤN ĐỀ}

Lao cột sống cổ (LCSC) it gặp so với lao cột sống ngực, thắt lưng, chỉ khoảng 5 -12 \% các lao cột sống. Tuy ít gặp nhưng nhiều biến chứng và thường nặng. Biến chứng thân kinh như liệt vận động tứ chi, rối loạn cơ tròn bàng quang, biến dạng cột sống cổ khoảng 40\% [2]. Điêuu trị phẫu thuật giải ép, cắt thân đốt sống hoại tử sau đó ghép xương tự thân là cơ bản được Hodgson mô tả năm 1960. Tuy nhiên biến chứng do mảnh xương ghép di lệch, cắt nhiều thân đốt sống đoạn xương ghép quá dài dễ di lệch, gãy mảnh ghép, bệnh nhân phải nằm bất động lâu sau mổ gây nhiều lo lắng, khó khăn cho bệnh nhân cũng như người thân. Ứng dụng lồng không kéo giãn được thực hiện từ rất sớm, liên xương tốt, bệnh nhẩn vận động sớm. Lông kéo giãn ADD được ứng dụng trển thế giới từ 2003 bước đâu kết quả khả quan được nhiều tác giả báo cáo [5]. Ở Việt Nam, có rất ít báo cáo về ứng dụng $A D D$. Vì vậy chúng tôi thực hiện nghiên cứu "điều trị phẩu thuật lao cột sống cổ đang hoạt động"

\section{II. ĐỐI TƯợNG VÀ PHƯƠNG PHÁP NGHIÊN CỨU \\ 2.1. Đối tượng nghiên cứu}

- 31 bênh nhân được chẩn đoán LCSC có chỉ định phẫu thuật thời gian từ $1 / 1 / 2015$ đến 30/9/2017 tại Bệnh viện Phổi Trung ương.

- Tiêu chuẩn lựa chọn: bệnh nhân lao cột sống cổ từ C2 - C7 có chỉ định phẫu thuât lối cổ trước hoặc ghép xương tự thân hoặc phẫu thuật đặt lồng kéo giãn ADD; điều trị thuốc chống lao trước mổ ít nhất 1 tuân theo phác đồ 2RHZE/10RHE; XQ CSC nghiêng: xẹp đĩa đệm, xẹp thân đốt sống, tăng khoảng mờ trước cột sống, biến dạng cột sống; CLVT CSC: hình ảnh phá hủy thân đốt sống biểu hiện tiêu xương bờ không rõ ràng, có mảnh xương chết trong chất hoại tử hoặc trong áp xe, xẹp đĩa đệm; CHT cột sống cổ: có áp xe hoặc chất hoại tử cạnh sống, ngoài màng cứng hoặc trong thân đốt sống, chèn ép tủy và màng cứng và đồng ý tham gia nghiên cứu.

\subsection{Phương pháp nghiên cứu}

- Thiết kế nghiên cứu: nghiên cứu cắt ngang. 
- Kỹ thuật chọn mẫu: chọn mẫu chủ đích với 31 bệnh nhân bị LCSC được phẫu thuât lối cổ trước và phân bổ 15 bệnh nhân vào phẫu thuật ghép xương tự thân, 16 bệnh nhân được phần bổ vào phẫu thuật đặt lồng ADD

- Biến số nghiên cứu: tỷ lệ thời gian trung bình phẫu thuật cho mối phương pháp; tỷ lệ số thân đốt sống cổ được cắt lúc mổ; thời gian nằm viện trung bình; mức độ cải thiện đau theo thang VAS sau mổ; góc gù vùng sau mổ 1 tuần, góc gù cột sống và lần khám cuối cùng.

- Các bước phẫu thuật

+ Bệnh nhân nằm ngửa trên bàn phẫu thuật, cổ hơi ưỡn, rạch da theo đường Southwick Robinson (hình 1.A);
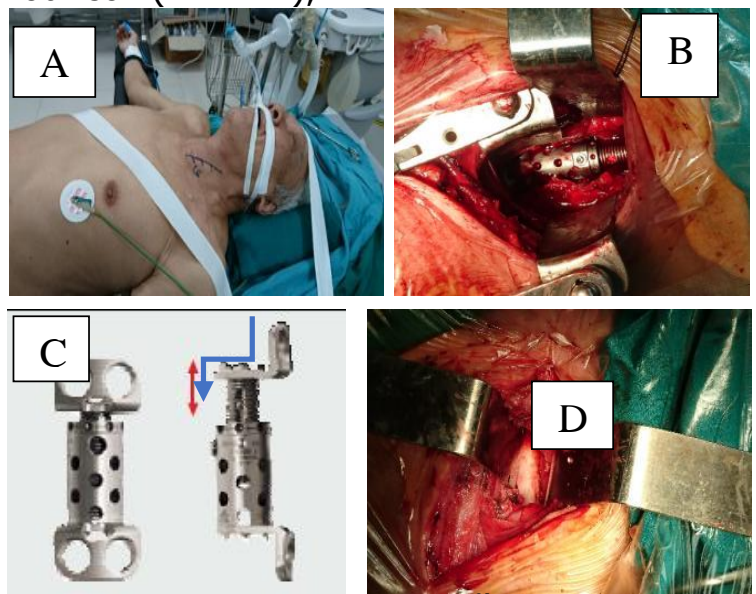

Hinh 1: Các thi phẫu thuật

+ Sau khi cắt lọc, cắt thân đốt sống giải ép và đặt $A D D^{\text {plus }}$ (hình $1 B$ ); đặt khối xương chậu ghép (hình 1D)
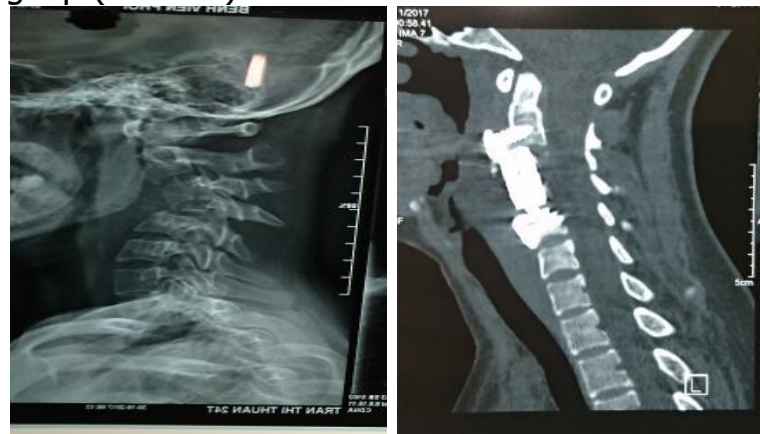

Hình 2: hình ảnh XQ trước mố và sau mổ đăt ADDplus của bệnh nhân nghiên cứu

- Quản lý và xử lý số liệu: số liệu sau khi thu thập (khám và đo gù, vẹo... trên phim XQ) nhờ vào sự hỗ trợ phần mềm SPSS 20.0 để tính.

- Một số khái niệm trong nghiên cứu: chúng tôi quy ước gọi nhóm bệnh nhân phẫu thuật có đặt lồng kéo giãn (ADD plus hoặc $A D D)$ là nhóm II $(n=16)$, nhóm phấu thuật chỉ ghép xương tự thân là nhóm I $(n=15)$.

\section{KẾT QUẢ NGHIÊN CứU}

3.1. Đặc điểm chính của phẫu thuật qua đường cổ trước. Thời gian mổ trung bình nhóm II là $138,1 \pm 40,6$ phút, nhóm I là 105,0 $\pm 23,4$ phút, khác nhau giữa thời mổ giữa 2 phương pháp có ý nghĩa thống kê $p=0,01$. Thời gian mổ ở II ngắn nhất là 70 phút, dài nhất là 250 phút. Thời gian mổ nhóm I ngắn nhất là 65 phút, dài nhất là 165 phút.

Bảng 1: Số thân đôt sống cổ được cắt lúc phẫu thuật

\begin{tabular}{|c|c|c|c|c|c|c|}
\hline \multirow{3}{*}{ Số thân đốt sống cắt } & \multicolumn{4}{|c|}{ Nhóm nghiên cứu } & \multirow{2}{*}{\multicolumn{2}{|c|}{ Cộng }} \\
\hline & \multicolumn{2}{|c|}{ Nhóm II } & \multicolumn{2}{|c|}{ Nhóm I } & & \\
\hline & $\mathbf{n}$ & $\%$ & $\mathbf{n}$ & $\%$ & $\mathbf{n}$ & $\%$ \\
\hline 1 thân & 1 & 6,2 & 0 & 0,0 & 1 & 3,2 \\
\hline$\geq 2$ thân & 10 & 62,5 & 5 & 33,3 & 15 & 48,4 \\
\hline Môt phần mỗi thân & 5 & 31,2 & 10 & 66,7 & 15 & 48,4 \\
\hline Công & 16 & 100,0 & 15 & 100,0 & 31 & 100,0 \\
\hline$-P$ & \multicolumn{6}{|c|}{0,001} \\
\hline $\bar{X} \pm S D$ & & & & 0,6 & & \\
\hline
\end{tabular}

Ớ nhóm II số bệnh nhân phấu thuật cắt $\geq 2$ thân đốt sống là $10(62,5 \%)$ trong khi nhóm I là $33,3 \%$. Ngược lại, nhóm I, cắt một phần mỗi thân đốt sống là $66,7 \%$ (10 bệnh nhân). Khác biệt giữa 2 nhóm có ý nghĩa thống kê với $\mathrm{p}=0,001$.

Bảng 2: Thời gian nằm viện

\begin{tabular}{|c|c|c|c|c|}
\hline \multirow{2}{*}{$\begin{array}{c}\text { Nhóm } \\
\text { nghiên cứu }\end{array}$} & \multicolumn{3}{|c|}{ Thời gian nằm viện (ngày) } \\
\cline { 3 - 5 } & $\overline{\mathrm{X}}$ & SD & $\begin{array}{c}\text { Tối } \\
\text { thiểu }\end{array}$ & Tối đa \\
\hline Nhóm II $(\mathrm{n}=16)$ & 39,75 & 25,4 & 18 & 107 \\
Nhóm I $(\mathrm{n}=15)$ & 43,13 & 19,5 & 15 & 83 \\
\hline Chung cả hai & 41,39 & 22,4 & 15 & 107 \\
\hline
\end{tabular}

\begin{tabular}{|c|c|c|c|c|}
\hline nhóm & & & \\
\hline$P$ & \multicolumn{3}{|c|}{0,682} \\
\hline
\end{tabular}

Thời gian nằm viện trung bình của 31 bệnh nhân là $41,39 \pm 22,4$ ngày, nằm ngắn nhất 15 ngày và lâu nhất 107 ngày. Thời gian nằm viện trung bình của nhóm II là $39,75 \pm 25,4$ ngày, nằm ngắn nhất 18 ngày và lâu nhất 107 ngày. 
Thời gian nằm viện trung bình của nhóm I là $43,13 \pm 19,5$ ngày, nằm ngắn nhất 15 ngày và lâu nhất 83 ngày. Không có sự khác nhau về thời gian nằm viện giữa 2 phương pháp điều trị $(p=$ 0,682).

Bảng 3: Thời gian theo dôi sau mổ

\begin{tabular}{|c|c|c|c|c|}
\hline \multirow{2}{*}{$\begin{array}{l}\text { Nhóm } \\
\text { nghiên cứu }\end{array}$} & \multicolumn{4}{|c|}{$\begin{array}{l}\text { Thời gian theo dõi } \\
\text { sau mố (tháng) }\end{array}$} \\
\hline & $\overline{\mathrm{X}}$ & SD & $\begin{array}{c}\text { Tôîi } \\
\text { thiểu }\end{array}$ & $\begin{array}{l}\text { Tối } \\
\text { đa }\end{array}$ \\
\hline Nhóm II $(n=16)$ & 17,1 & 8,4 & 3 & 32 \\
\hline Nhóm I $(\mathrm{n}=15)$ & 13,7 & 9,4 & 3 & 32 \\
\hline Chung cả hai nhóm & 15,4 & 8,9 & 3 & 32 \\
\hline 8 & \\
\hline
\end{tabular}

Thời gian theo dõi trung bình của cả hai phương pháp là $15,4 \pm 8,9$ tháng, ít nhất là 3 tháng và nhiêu nhất là 32 tháng. Thời gian theo dõi trung bình của nhóm II là 17,1 \pm 8,4 tháng, ít nhất là 3 tháng và nhiều nhất là 32 tháng. Thời gian theo dõi trung bình của nhóm I là $13,7 \pm$ 9,4 tháng, ít nhất là 3 tháng và nhiều nhất là 32 tháng. Không có sự khác nhau về thời gian theo dõi sau mổ giữa 2 phương pháp điều trị I và II với $\mathrm{p}=0,298$.

3.2. Đánh giá cải thiện lâm sàng sau phấu thuật

Bảng 4: So sánh VAS trung bình giữa 2 nhóm 12 tháng sau mổ

\begin{tabular}{|c|c|c|c|}
\hline VAS & Nhóm I & Nhóm II & Chung \\
\hline$X$ & 0,25 & 0,08 & 0,14 \\
\hline SD & 0,5 & 0,3 & 0,4 \\
\hline N & 8 & 13 & 21 \\
\hline P & \multicolumn{3}{|c|}{0,294} \\
\hline
\end{tabular}

Ớ thời điểm 12 tháng sau phầu thuật, ở nhóm I mức độ đau theo VAS là $0,08 \pm 0,3$, trong khi đó ở nhóm II mức độ đau theo VAS là $0,25 \pm 0,5$. Sự khác nhau về mức độ đau theo VAS giữa 2 nhóm bệnh nhân không có ý nghĩa thống kê $(p=0,294)$.

Bảng 5: Góc gù̀ vùng sau mổ 1 tuần so sánh giữa 2 nhóm

\begin{tabular}{|c|c|c|c|c|}
\hline Nhóm & $\bar{X}$ & SD & $\begin{array}{c}\text { Nhó } \\
\text { nhất }\end{array}$ & $\begin{array}{c}\text { Lớn } \\
\text { nhất }\end{array}$ \\
\hline II $(n=16)$ & $-5,19^{0}$ & $6,2^{0}$ & $-13^{0}$ & $12^{0}$ \\
\hline I $(n=15)$ & $5,8^{0}$ & $11,2^{0}$ & $-9^{0}$ & $28^{0}$ \\
\hline Chung $(n=31)$ & $0,13^{0}$ & $10,4^{0}$ & $-13^{0}$ & $28^{0}$ \\
\hline$P$ & \multicolumn{4}{|c|}{0,002} \\
\hline
\end{tabular}

Góc gù vùng trung bình sau mố 1 tuần ở nhóm I là $5,8^{\circ} \pm 11,2^{\circ}$. Góc gù vùng trung bình sau mổ 1 tuần ở nhóm II là $-5,19^{\circ} \pm 6,2^{\circ}$. Sự khác nhau về góc gù vùng sau mổ 1 tuần giữa 2 phương pháp rất có ý nghĩa thống kê $(p<0,01)$.

Bảng 6: Góc gù vùng khám lân cuôi cùng sau mổ so sánh giữa 2 nhóm

\begin{tabular}{|c|c|c|c|c|}
\hline Nhóm & $\bar{X}$ & SD & $\begin{array}{c}\text { Nhó } \\
\text { nhất }\end{array}$ & $\begin{array}{c}\text { Lớn } \\
\text { nhất }\end{array}$ \\
\hline II $(n=11)$ & $-7,0^{0}$ & $4,0^{0}$ & $-14^{0}$ & $-2^{0}$ \\
\hline I $(n=7)$ & $4,14^{0}$ & $12,3^{0}$ & $-8^{0}$ & $30^{0}$ \\
\hline Chung $(n=18)$ & $-2,67^{0}$ & $10,0^{0}$ & $-14^{0}$ & $30^{0}$ \\
\hline$P$ & \multicolumn{4}{|c|}{0,015} \\
\hline
\end{tabular}

Ở lần khám cuối cùng nhóm II có 11 bệnh nhân, nhóm I có 7 bệnh nhân được theo dõi. Góc gù vùng cuối cùng sau mổ ở nhóm I là $4,14^{\circ}$ $\pm 12,3^{\circ}$. Góc gù vùng cuối cùng sau mổ ở nhóm II là $-7,0^{\circ} \pm 4,0^{\circ}$. Sự khác nhau về góc gù vùng sau khám lần cuối cùng giữa 2 nhóm điều trị có ý nghĩa thống kê $(p=0,015)$.

Bảng 7: Góc cốt sống cổ 1 tuân sau mổ giữa 2 nhóm bệnh nhân

\begin{tabular}{|c|c|c|c|}
\hline $\begin{array}{c}\text { Góc cột } \\
\text { sống cổ }\end{array}$ & Nhóm II & Nhóm I & Chung \\
\hline $\mathrm{N}$ & 16 & 15 & 31 \\
\hline $\mathrm{X}$ & $-9,31^{0}$ & $-11^{0}$ & $-10,13^{0}$ \\
\hline $\mathrm{SD}$ & $6,5^{0}$ & $11,0^{0}$ & $8,8^{0}$ \\
\hline $\mathrm{P}$ & \multicolumn{3}{|c|}{0,604} \\
\hline
\end{tabular}

Góc cột sống cổ sau mổ 1 tuần ở nhóm $\mathrm{A}$ là $11,0^{0} \pm 11,0^{0}$. Góc cột sống cổ sau mổ 1 tuần ở nhóm $B$ là $-9,31^{0} \pm 6,5^{\circ}$. Sự khác nhau về góc gù cột sống sau mổ 1 tuần giứa 2 nhóm không có ý nghĩa thống kê $(p>0,05)$.

Bảng 8: Góc cột sông cổ giữa 2 nhóm ở lân khám cuôî cùng

\begin{tabular}{|c|c|c|c|c|}
\hline Nhóm & $\bar{X}$ & SD & $\begin{array}{c}\text { Nhó } \\
\text { nhất }\end{array}$ & $\begin{array}{c}\text { Lớn } \\
\text { nhất }\end{array}$ \\
\hline $\begin{array}{c}\text { Nhóm } B \\
(n=11)\end{array}$ & $-9,6^{0}$ & $7,2^{0}$ & $-18^{0}$ & $10^{0}$ \\
\hline $\begin{array}{c}\text { Nhóm } A \\
(n=7)\end{array}$ & $-9,3^{0}$ & $13,0^{0}$ & $-24^{0}$ & $17^{0}$ \\
\hline $\begin{array}{c}\text { Chung } \\
(n=18)\end{array}$ & $-9,4^{0}$ & $9,5^{0}$ & $-24^{0}$ & $17^{0}$ \\
\hline$P$ & \multicolumn{4}{|c|}{0,957} \\
\hline
\end{tabular}

Góc cột sống cố sau mổ ở lần khám cuối cùng ở nhóm A là $-9,3^{0} \pm 13,0^{\circ}$. Góc cột sống cổ sau mổ ở lần khám cuối cùng ở nhóm $B$ là $-9,6^{0} \pm$ $7,2^{\circ}$. Sự khác nhau về góc gù cột sống sau mổ 1 tuần giửa 2 nhóm không có ý nghĩa thống kê ( $p$ $>0,05$ ).

\section{BÀN LUÂ̂N}

- Kết quả nghiên cứu của Koptan và cs (2011) [1] 30 bệnh nhân lao cột sống cổ chia 2 nhóm, nhóm chỉ ghép xương và nhóm đặt lồng không kéo giãn (NETC). Kết quả thời gian phẩu thuật nhóm ghép xương là 125 phút, nhóm đặt lồng là 100 phút. Thời gian cho phẫu thuật ghép xương lâu hơn là do có thêm phấu thuật cắt khối xương mào chậu. Trong nhóm đặt lồng, tác giả sử dụng lồng khồng kéo giãn ngẵn vì lî̀ng không có vít cố định, và lồng đã chuẩn bị sẵn trước mổ nên thời 
gian ngắn hơn. Kết quả của chúng tôi, thời gian mổ ở nhóm ghép xương tự thân là 105 phút. Nhóm đặt $A D D^{\text {plus }}$ là 138,1 phút. Kết quả nghiên cứu của Hao Zeng và cs [2] thời gian phẫu thuật trung bình $225 \pm 39$ phút, thời gian nằm viện $15,2 \pm 4,5$ ngày. Thời gian mổ trong nghiên cứu này dài hơn kết quả nghiên cứu của chúng tôi vì chúng tôi chỉ mổ một lối vào trước, trong đó khi Hao Zeng và cs mổ cả lối trước và lối sau để cố định, ghép xương. Nhưng số ngày nằm viện ngắn hơn nghiên cứu của chúng tôi vì $B N$ nhẩn tham gia nghiên cứu của chúng tôi cần thời gian 2 tuần nằm viện để điều trị thuốc chống lao trước mổ, đồng thời BN nhập viện thường có nhiêu bệnh kèm theo như tim mạch, dùng thuốc chống đông, mắc lao đoạn cột sônng khác kèm theo, khớp khác kèm theo có chỉ định mổ nên thời gian nằm viện kéo dài hơn.

- Việc lựa chọn cách hàn liên thân đốt sống sau khi cắt thân đốt sống bằng ghép xương tự thân hoặc lồng không kéo giãn hoặc lồng kéo giãn được (ETC) được nhiều tác giả báo cáo [3]. Mỗi phương pháp có ưu và nhược điểm riêng nhưng tăng tỉ lệ biến chứng khi cắt nhiều thân đốt sống. Có rất ít báo cáo về phẫu thuật lao cột sống cố cắt nhiều thân đốt sống ( $\geq 3$ thân đốt sông), Hao Zeng và cs (2016) đã nghiên cứu 11 bệnh nhân phẫu thuật cả lối trước cắt thân đốt sổng, ghép xương đồng loại và lối sau nẹp vít cố định khối bên, ghép xương sau bên. Tất cả bệnh nhân đều phải nằm bất động sau mổ, thời gian liền xương đạt được từ 6 đến 9 tháng ở tất cả 11 bệnh nhân [2]. Các biến chứng liên quan đến lồng không kéo giãn là di lệch và biến dạng vùng của cột sống cổ đã được báo cáo [4]. Kết quả nghiên cứu của Tarantino và cs (2017) trên 34 bệnh mổ lối cổ trước cắt thân đốt sống và đặt ADD plus, cắt 1 thân đốt sống $21 / 34$ bênh nhẩn $(61,8 \%)$, cắt 2 thân đốt sống $9 / 34(26,5 \%)$, và cắt 3 thân đốt sống ở 4/34 bệnh nhân. Tuy nhiên, tác giả ứng dụng $A D D^{\text {plus trong nghiên }}$ cứu này là để điều trị thoái hóa cột sống cổ nên số bệnh nhân cắt 1 thân đốt sống chiếm đa số [5].

Kết quả nghiên cứu của Nigro L và cs (2017) có 1 bệnh nhân cắt 2 thân đốt sống do lao cột sống cổ có gù nặng, kết quả chỉnh gù tốt, tỉ lệ di lệch $A D D^{p l u s}$ thấp và kỹ thuật dễ thực hiện hơn [6]. Kết quả nghiên cứu của Zhang và cs (2018) có 1 bệnh nhân lao cột sống cổ mổ cắt 4 thân đốt sống sau đó ghép xương mác tự thân dài $9,5 \mathrm{~cm}$. Bệnh nhân này được phẫu thuật cố định bằng nẹp vít qua cuống lối sau trước khi mổ lối trước. Kết quả liền xương đạt được 6 tháng sau phẫu thuật [7].
Mao He và cs (2014) mổ 25 bệnh nhân lao cột sống cổ thấp ghép xương tự thân và đặt nẹp cổ trước. Nằm bất động ngày đầu tiên sau mổ, ngày thứ 2 cho ngồi dậy, ngày thứ 3 hướng dẫn bệnh nhân đứng và đi. Tuy nhiên, bệnh nhân của tác giả được mổ cố định nẹp cổ trước nên hạn chế biến chứng di lệch mảnh xương ghép [3]. Nghiên cứu của chúng tôi, có 15 bệnh nhân ghép xương nhưng không cố định nẹp cổ trước, mặc dù không di lệch mảnh ghép nhưng bệnh nhân phải nằm bất động sau mổ lâu hơn với thời gian trung bình là $24,1 \pm 18$ ngày. Khi so sánh với nhóm đặt $A D D^{\text {plus }}$, thời gian bất động ngắn hơn $10,6 \pm 6,6$ ngày $(p<0,01)$.

Okada và cs (2009) báo cáo 15 bệnh nhân lao cột sống chỉ mổ lối cổ trước cắt thân đốt sống và ghép xương, nẹp cổ trước. Thời gian nằm viện trung bình là $190,5 \pm 34,8$ ngày. Kết quả nghiên cứu của chúng tôi thời gian nằm viện của chúng tôi, đối với bệnh nhân điều trị bằng phương pháp II là 39,75 $\pm 25,4$ ngày, nằm ngắn nhất 18 ngày và lâu nhất 107 ngày. Thời gian nằm viên trung bình của của phương pháp I là $43,13 \pm 19,5$ ngày, nằm ngắn nhất 15 ngày và lâu nhất 83 ngày. Như vậy kết quả nghiên cứu thời gian nằm viên của chúng tôi ít hơn so với kết quả nghiên cứu của tác giả.

Zeng và cs 2016 [2] báo cáo 12 BN LCSC trẻ em có gù nặng, được mổ cắt ít nhất 3 thân đốt sống, đặt lồng titan và cố định CSC lối sau. Mức độ đau VAS cải thiện $92,4 \%$ sau mổ. Tác giả đánh giá cải thiện chức năng thần kinh bằng thang điểm Frankel, có 3 BN phục hồi không hoàn toàn, mức $D$ ở lần khám cuối cùng do được chẩn đoán muộn. Tuy nhiên, đây là phương pháp mổ 2 lối trước và sau nhưng cải thiện mức độ đau VAS cũng tương tự chỉ mổ lối trước. Kết quả nghiên cứu của chúng tôi mức độ đau VAS cải thiện 1 tuần sau mổ trung bình là $61,03 \%$ và ở lần khám cuối cùng là 94,8\% $(p<0,01 X=$ 5,11; CI 95\%: 4,41 - 5,81.

Tarantino và Cs [5] báo cáo chỉnh gù tốt không di lệch, liền xương chắc sau 24 tháng ở $\mathrm{BN}$ cắt 1 hoặc nhiều thân đốt sống sau đó đặt $\mathrm{ADD}^{\text {plus }}$ [6], báo cáo của chúng tôi 16 BN LCSC, ghép xương mào chậu tự thân và nẹp cổ trước, kết quả tất cả $B N$ đều liền xương và chỉnh gù trung bình từ $21,6^{0}$ trước mổ giảm còn $2,5^{0}$ ở lần khám cuối cùng. Koptan và cs [1] thông báo 30 BN LCSC chia 2 nhóm, nhóm I mổ lối trước có dùng lồng titan, và nhóm II chỉ ghép xương mào chậu tự thân có nẹp cổ trước, theo dõi 2 năm đánh giá kết quả. Mức độ đau VAS nhóm I giảm từ 8 xuống $1,5(81,3 \%)$ điểm và từ 8,5 xuống 
$2,5(70,6 \%)$ ở nhóm II. Phục hồi liệt hoàn toàn (Frankel $\mathrm{E}$ ) cả 2 nhóm ở thời điểm khám cuối cùng và không khác biệt về phục hồi chức năng tủy cổ giữa 2 nhóm, tỉ lệ chỉnh gù sau mổ ở nhóm I trung bình là $36^{\circ}$ còn $-6^{0}(96 \%)$ trong khi nhóm II chỉnh gù được $84 \%\left(30^{\circ}\right.$ về $\left.-1^{0}\right)$ [1]. Kết quả nghiên cứu của Zeng và cs báo cáo chỉnh gù cột sống cổ $C 2-C 7$ từ $41,4^{0} \pm 5,2^{\circ}$ trước mổ còn $-4,9^{0} \pm 4,9^{\circ}$ sau mổ.

\section{KẾT LUÂN}

Phẫu thuật điều trị lao cột sống cổ kết quả tốt, vừa chỉnh gù cột sống, vừa không bị đào thải dụng cụ ngay cả khi lao cột sống đang hoạt động và bệnh nhân vận động sớm.

\section{TÀI LIÊU THAM KHẢO}

1. W. Koptan, Y. Elmiligui, M. Elsharkawi (2011). Single stage anterior reconstruction using titanium mesh cages in neglected kyphotic tuberculous spondylodiscitis of the cervical spine. Eur Spine J, 20(2), 308-313.

2. Hao Zeng, Yupeng Zhang, Zheng Liu, et al. (2016). The role of anterior and posterior approaches with circumferential reconstruction without any anterior instrumentation in extended multilevel cervical spinal tuberculosis. int J Clin Exp Med, 9(3), 6190-6199.

3. M. He, H. $\mathrm{Xu}, \mathrm{J}$. Zhao, Z. Wang (2014). Anterior debridement, decompression, bone grafting, and instrumentation for lower cervical spine tuberculosis. Spine J, 14(4), 619-627.

4. M. S. Moon, S. S. Kim, Y. W. Moon, et al. (2014). Surgery-related complications and sequelae in management of tuberculosis of spine. Asian Spine J, 8(4), 435-445.

5. R. Tarantino, L. Nigro, P. Donnarumma, et al. (2017). Cervical reconstruction techniques. After adequate selection of the patient report of a series of 34 patients treated with winged expandable cages. Neurosurg Rev, 40(2), 281-286.

6. L. Nigro, R. Tarantino, P. Donnarumma, et al. (2017). A case of cervical tuberculosis with severe kyphosis treated with a winged expandable cage after double corpectomy. J Spine Surg, 3(2), 304-308.

7. J. Zhang, W. S. He, C. Wang, et al. (2018). Application of vascularized fibular graft for reconstruction and stabilization of multilevel cervical tuberculosis: A case report. Medicine (Baltimore), 97(3), e9382.

\section{ĐĂC ĐIỂM LÂM SÀNG VÀ HÌNH ẢNH CẮT LỚP VI TÍNH 64 DÃY MẠCH NÃO Ở BỆNH NHÂN CHẢY MÁU NÃO DO Vỡ DỊ DẠNG THÔNG ĐộNG-TĨNH MẠCH NÃO}

\section{TÓM TẮT.}

Mục tiêu: Mô tả đặc điểm lâm sàng, hình ảnh chụp MSCT 64 dãy ở bệnh nhân chảy máu não do võ̃ dị danng thông đông tînh mạch não (AVM). Đối tượng nghiên cứu: Tất cả các bệnh nhân được chẩn đớán là dị dạng thông động-tĩnh mạch não có biến chứng chảy máu được chụp MSCT 64 dãy não-mạch não điêu trị tại Bệnh viện Bạch Mai từ 10/2019 đển 07/2021. Phương pháp nghiên cứu: Mô tả cắt ngang. Kết quả: Tuổi trung bình của nhóm bệnh nhân AVM vỡ là $43 \pm 14,7$ tuổi, tỳ lệ nam/nữ = 1,27/1. Tiền sử bệnh nhân có nhức đâu trước đó chiếm $69,44 \%$, tiền sử động kinh $25 \%$. Tiền sử gia đình có người bị nhức đâu chiếm tỳ lệ cao nhất chiếm $63,89 \%$, dị dạng mạch ngoài da chiếm $11,11 \%$. Bệnh nhân vào vieên vì buiôn nôn, nôn chiếm tỷ lệ $97,2 \%$, vì đau đâuu chiểm $94,4 \%$, vì liệt nửa người chiếm $50 \%$, vì rối loạn ý thức chiếm $30,56 \%$. Vị trí chảy máu hay gặp là chảy máu thùy.

\footnotetext{
${ }^{1}$ Bệnh viện Bạch Mai

2 Trường Đại họ Y Hà Nôi

${ }^{3}$ Bênh Viện Đa khoa tỉnh Thanh Hóa.

Chịu trách nhiệm chính: Võ Hồng Khôi

Email: drvohongkhoi@yahoo.com.vn

Ngày nhận bài: 8.9.2021

Ngày phản biện khoa học: 27.10.2021

Ngày duyệt bài: 10.11.2021
}

Võ Hồng Khôi i, ${ }^{1,2}$ Lê Hồng Ninh ${ }^{3}$, Nguyễn Hải Anh ${ }^{1}$.

Kích thước khối máu tụ nhỏ, trung bình và lớn lần lượt chiếm $26,47 \%, 41,18 \%$ và $32,35 \%$. Các ổ dị dạng có kích thước nhỏ và trung bình là hay võ̃ nhất chiếm 97,2\%. Nguồn cấp máu cho ổ dị dạng vỡ çủa động mạch não giữa là nhiều nhất chiếm $52,78 \%$. Ổ dị dạng được nuôi bằng 1 đến 3 cuống nuôi (chiếm 91,67\%) và có một tĩnh mạch dẫn lưu duy nhất (chiếm 72,2\%) là những ổ dễ vỡ. Kết luận: Độ tuổi hay gặp nhất của các bệnh nhân AVM võ là trền 40 tuổi chiếm tỷ lệ $63,9 \%$; tuổi trung bình $43 \pm 14,7$. Bệnh gặp ở cả hai giới với tỷ lệ nam/nữ là 1,27/1. Bệnh nhân vào viện vì buồn nôn, nôn chiếm $97,2 \%$, đau đâu $94,4 \%$, liệt nửa người chiếm $50 \%$, rối loạn ý thức $30 \%$, động kinh $13,89 \%$. Chảy máu do võ AVM là chảy máu thùy chiếm $85,72 \%$. Ổ dị dạng vỡ thường là ổ có kích thước nhỏ $<3 \mathrm{~cm}$, có một tĩnh mạch dẫn lưu duy nhất.

Tư khóa: Dị dạng thông động tînh mạch não võ, MSCT 64 dãy não-mạch não.

\section{SUMMARY}

CLINICAL FEATURES AND MSCT IMAGING

IN PATIENTS WITH RUPTURED CEREBRAL ARTERIOVENOUS MALFORMATION

Objectives: To describe clinical features and MSCT imaging in cerebral hemorrhage patients due to ruptured cerebral arteriovenous malformation. Methods: A descriptive cross-sectional study of 36 cases with ruptured cerebral arteriovenous 